\title{
Synthesis, Antitumor Evaluation and Apoptosis-Inducing Activity of Hydroxylated (E)-Stilbenes
}

Cedric J. Lion, Charles S. Matthews, Malcolm F.G. Stevens and Andrew D. Westwell

\section{Supporting Information}

\section{Contents:}

- Preparative methods for substituted benzyl phosphonic acid diethyl esters and MOM-protected hydroxy benzaldehydes (3ax - 3jz), and hydroxylated stilbenes $(\mathbf{5} \mathbf{a x}-\mathbf{5 j} \mathbf{j})$

- Characterisation data for MOM-protected hydroxy-stilbenes (3ax - 3jz)

- Characterisation data for hydroxy-stilbenes $(\mathbf{5 a x}-\mathbf{5 j z})$

- Protocols for in vitro biological assays: growth inhibition, cell cycle analysis, AnnexinV-FITC/propidium iodide analysis of apoptosis, fluorescence microscopy

- Table of $\mathrm{GI}_{50}$ values in MDA MB 435 and HCT 116 cell lines

- Elemental analysis data (\% C, H) for compounds $\mathbf{5 a x}-\mathbf{5 j z}$

- Figure S1 showing AnnexinV-PI analysis in MDA MB 468 cells, following 48 h drug treatment with camptothecin $(250 \mathrm{nM})$, resveratrol $(10 \mu \mathrm{M})$, and doseresponse profile of compound $\mathbf{5 d y}(1,10$ and $50 \mu \mathrm{M})$ 


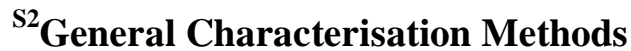

Melting points were recorded on a Gallenkamp melting point apparatus, and are uncorrected. ${ }^{1} \mathrm{H}$ spectra were recorded on a Bruker ARX250 spectrometer at 250.1 and 62.9 MHz, respectively, in solvents as specified, with tetramethylsilane or residual protic solvents as internal standard. $J$ values are in Hz. Low resolution mass spectra were recorded on a Micromass Platform $\left(\mathrm{AP}^{+}, \mathrm{ES}^{+}\right)$. High resolution mass spectrometry (HRMS) was carried out by the services provided by the School of Chemistry, University of Nottingham and EPSRC National Mass Spectrometry Service Centre, Swansea, U.K. Silica gel TLC was performed on 60F-254 pre-coated sheets (Merck). Elemental analyses were carried out by the microanalysis service, School of Chemistry, University of Nottingham.

General method for the preparation of substituted benzyl phosphonic acid diethyl esters. Substituted benzyl bromide was heated with excess triethylphosphite at $140^{\circ} \mathrm{C}$ until the evolution of bromoethane had ceased and complete dissolution occurred. The remaining triethylphosphite was then removed by concentration of the solution in vacuo to afford the product (1a-j) sufficiently pure for subsequent transformations.

\section{General method for the preparation of MOM-protected hydroxy benzaldehydes.}

Hydroxylated benzaldehyde $(100 \mathrm{mmol})$ and Hunig's base $\left(\operatorname{NEt}(i \operatorname{Pr})_{2}, 110\right.$ mmol) were dissolved in dichloromethane $(50 \mathrm{~mL})$. The mixture was stirred for ten 
${ }^{\mathrm{S} 3}$ minutes then cooled to $0^{\circ} \mathrm{C}$. Chloromethylmethyl ether $(200 \mathrm{mmol})$ was then added dropwise and the mixture stirred at $25^{\circ} \mathrm{C}$ for two hours. The mixture was washed with brine $(3 \times 20 \mathrm{~mL})$ and $0.1 \mathrm{M} \mathrm{HCl}(3 \times 20 \mathrm{~mL})$, and the separated organic phase dried $\left(\mathrm{MgSO}_{4}\right)$, filtered and concentrated in vacuo to afford the MOM-protected hydroxy benzaldehyde $(\mathbf{2 x - z})$ as an oil.

\section{Characterisation Data for MOM-Protected Hydroxy-Stilbenes}

\section{(E)-1-Methoxymethyloxy-4-styrylbenzene (3ax).}

Precursor to commercially available (E)-1-hydroxy-4-styrylbenzene (5ax).

(E)-1-Methoxymethyloxy-3-styrylbenzene (3ay). Yield $=93 \% .{ }^{1} \mathrm{H} \mathrm{NMR}\left(\mathrm{CDCl}_{3}\right) \delta$ $7.44(2 \mathrm{H}, \mathrm{dd}, J=8.5,1.7 \mathrm{~Hz}, \mathrm{ArH}), 7.27(2 \mathrm{H}, \mathrm{dt}, J=7.0,1.7 \mathrm{~Hz}, \mathrm{ArH}), 7.19(2 \mathrm{H}, \mathrm{m}$, 1xArH, 1xCH=CH), $7.11(2 \mathrm{H}, \mathrm{m}, 1 \mathrm{xArH}, 1 \mathrm{xCH}=\mathrm{CH}), 7.00(2 \mathrm{H}, \mathrm{s}, \mathrm{ArH}), 6.88(1 \mathrm{H}$, ddd, $J=7.0,2.5,1.2 \mathrm{~Hz}, \mathrm{ArH}), 5.12\left(2 \mathrm{H}, \mathrm{s}, \mathrm{OCH}_{2} \mathrm{O}\right), 3.45\left(3 \mathrm{H}, \mathrm{s}, \mathrm{OCH}_{3}\right) . m / z 241$ $\left(\mathrm{M}^{+}+1\right), 209\left(\mathrm{M}^{+}-\mathrm{OMe}\right)$

(E)-1-Methoxymethyloxy-2-styrylbenzene (3az). Yield $=90 \% .{ }^{1} \mathrm{H}$ NMR $\left(\mathrm{CDCl}_{3}\right) \delta$ $7.63(1 \mathrm{H}, \mathrm{dd}, J=7.7,1.6 \mathrm{~Hz}, \mathrm{ArH}), 7.55(2 \mathrm{H}, \mathrm{m}, \mathrm{ArH}), 7.27(2 \mathrm{H}, \mathrm{m}, \mathrm{ArH}), 7.11(2 \mathrm{H}$, m, 1xArH, 1xCH=CH), $7.00(2 \mathrm{H}, \mathrm{s}, \mathrm{ArH}), 7.15(2 \mathrm{H}, \mathrm{m}, J=16.1 \mathrm{~Hz}, 1 \mathrm{xArH}$, $1 \times \mathrm{CH} H \mathrm{CH}), 5.21\left(2 \mathrm{H}, \mathrm{s}, \mathrm{OCH}_{2} \mathrm{O}\right), 3.50\left(3 \mathrm{H}, \mathrm{s}, \mathrm{OCH}_{3}\right) . \mathrm{m} / z 241\left(\mathrm{M}^{+}+1\right), 209\left(\mathrm{M}^{+}-\right.$ OMe). 
${ }^{\text {S4}}(\mathbf{E})-1-M e t h o x y m e t h y l o x y-4-(4-m e t h o x y)$ styrylbenzene $(3 \mathrm{bx})$. Yield $=73 \% .{ }^{1} \mathrm{H}$ NMR $\left(\mathrm{CDCl}_{3}\right) \delta 7.45(2 \mathrm{H}, \mathrm{d}, J=8.8 \mathrm{~Hz}, \mathrm{ArH}), 7.43(2 \mathrm{H}, \mathrm{d}, J=8.8 \mathrm{~Hz}, \mathrm{ArH}), 7.03$ $(2 \mathrm{H}, \mathrm{d}, J=8.8 \mathrm{~Hz}, \mathrm{ArH}), 6.93(2 \mathrm{H}, \mathrm{s}, 2 \mathrm{xCH}=\mathrm{CH}), 6.90(2 \mathrm{H}, \mathrm{d}, J=8.8 \mathrm{~Hz}, \mathrm{ArH}), 5.20$ $\left(2 \mathrm{H}, \mathrm{s}, \mathrm{OCH}_{2} \mathrm{O}\right), 3.86\left(3 \mathrm{H}, \mathrm{s}, \mathrm{OCH}_{3}\right), 3.49\left(3 \mathrm{H}, \mathrm{s}, \mathrm{OCH}_{3}\right) . \mathrm{m} / z 271\left(\mathrm{M}^{+}+1\right)$.

(E)-1-Methoxymethyloxy-3-(4-methoxy)styrylbenzene (3by). Yield $=65 \%$. ${ }^{1} \mathrm{H}$ NMR $\left(\mathrm{CDCl}_{3}\right) \delta 7.46(2 \mathrm{H}, \mathrm{d}, J=8.7 \mathrm{~Hz}, \mathrm{H}-2, \mathrm{H}-6), 7.25(3 \mathrm{H}, \mathrm{m}, \mathrm{ArH}), 7.09(1 \mathrm{H}, \mathrm{d}, J$ $=16.9 \mathrm{~Hz}, \mathrm{CH}=\mathrm{CH}), 6.91(4 \mathrm{H}, \mathrm{m}, 1 \mathrm{xCH}=\mathrm{CH}, 3 \mathrm{xArH}), 5.25\left(2 \mathrm{H}, \mathrm{s}, \mathrm{OCH}_{2} \mathrm{O}\right), 3.87$ $\left(3 \mathrm{H}, \mathrm{s}, \mathrm{OCH}_{3}\right), 3.53\left(3 \mathrm{H}, \mathrm{s}, \mathrm{OCH}_{3}\right) . m / z 271\left(\mathrm{M}^{+}+1\right), 239\left(\mathrm{M}^{+}-\mathrm{OMe}\right)$.

(E)-1-Methoxymethyloxy-2-(4-methoxy)styrylbenzene (3bz). Yield $=64 \% .{ }^{1} \mathrm{H}$ NMR $\left(\mathrm{CDCl}_{3}\right) \delta 7.61(1 \mathrm{H}, \mathrm{dd}, J=7.7,1.6 \mathrm{~Hz}, \mathrm{ArH}), 7.50(2 \mathrm{H}, \mathrm{d}, J=8.6 \mathrm{~Hz}, \mathrm{H}-2, \mathrm{H}-$ 6), $7.39(1 \mathrm{H}, \mathrm{d}, J=16.4 \mathrm{~Hz}, \mathrm{CH}=\mathrm{CH}), 7.13(4 \mathrm{H}, \mathrm{m}, 1 \mathrm{xCH}=\mathrm{CH}, 3 \mathrm{xArH}), 6.91(2 \mathrm{H}, \mathrm{d}$, $J=8.6 \mathrm{~Hz}, \mathrm{H}-3, \mathrm{H}-5), 5.24\left(2 \mathrm{H}, \mathrm{s}, \mathrm{OCH}_{2} \mathrm{O}\right), 3.90\left(3 \mathrm{H}, \mathrm{s}, \mathrm{OCH}_{3}\right), 3.50\left(3 \mathrm{H}, \mathrm{s}, \mathrm{OCH}_{3}\right)$. $m / z 271\left(\mathrm{M}^{+}+1\right), 239\left(\mathrm{M}^{+}-\mathrm{OMe}\right)$.

(E)-1-Methoxymethyloxy-4-(3-methoxy)styrylbenzene (3cx). Yield $=86 \% .{ }^{1} \mathrm{H}$ NMR $\left(\mathrm{CDCl}_{3}\right) \delta 7.44(2 \mathrm{H}, \mathrm{d}, J=8.7 \mathrm{~Hz}, \mathrm{H}-3, \mathrm{H}-5), 7.21(1 \mathrm{H}, \mathrm{t}, J=7.8 \mathrm{~Hz}, \mathrm{ArH})$, $7.01(5 \mathrm{H}, \mathrm{m}, 1 \mathrm{xCH}=\mathrm{CH}, 4 \mathrm{xArH}), 6.97(1 \mathrm{H}, \mathrm{d}, J=16.3 \mathrm{~Hz}, \mathrm{CH}=\mathrm{CH}), 6.80(1 \mathrm{H}, \mathrm{ddd}$, $J=7.8,2.5,1.7 \mathrm{~Hz}, \mathrm{ArH}), 5.18\left(2 \mathrm{H}, \mathrm{s}, \mathrm{OCH}_{2} \mathrm{O}\right), 3.82\left(3 \mathrm{H}, \mathrm{s}, \mathrm{OCH}_{3}\right), 3.49(3 \mathrm{H}, \mathrm{s}$, $\left.\mathrm{OCH}_{3}\right) \cdot m / z 271\left(\mathrm{M}^{+}+1\right)$.

(E)-1-Methoxymethyloxy-3-(3-methoxy)styrylbenzene (3cy). Yield $=95 \% .{ }^{1} \mathrm{H}$ $\operatorname{NMR}\left(\mathrm{CDCl}_{3}\right) \delta 7.29(2 \mathrm{H}, \mathrm{t}, J=7.7 \mathrm{~Hz}, \mathrm{ArH}), 7.16(4 \mathrm{H}, \mathrm{m}, \mathrm{ArH}), 7.06(2 \mathrm{H}, \mathrm{s}$, 
$\left.{ }^{\mathrm{S} 5} 2 \mathrm{xCH}=\mathrm{CH}\right), 6.94(1 \mathrm{H}, \mathrm{ddd}, J=7.8,2.1,1.6 \mathrm{~Hz}, \mathrm{ArH}), 6.85(1 \mathrm{H}, \mathrm{ddd}, J=7.8,2.5$, $1.7 \mathrm{~Hz}, \mathrm{ArH}), 5.21\left(2 \mathrm{H}, \mathrm{s}, \mathrm{OCH}_{2} \mathrm{O}\right), 3.83\left(3 \mathrm{H}, \mathrm{s}, \mathrm{OCH}_{3}\right), 3.50\left(3 \mathrm{H}, \mathrm{s}, \mathrm{OCH}_{3}\right) . m / z 271$ $\left(\mathrm{M}^{+}+1\right)$.

(E)-1-Methoxymethyloxy-2-(3-methoxy)styrylbenzene (3cz). Yield $=92 \% .{ }^{1} \mathrm{H}$ $\operatorname{NMR}\left(\mathrm{CDCl}_{3}\right) \delta 7.62(1 \mathrm{H}, \mathrm{dd}, J=7.7,1.6 \mathrm{~Hz}, \mathrm{ArH}), 7.52(1 \mathrm{H}, \mathrm{d}, J=16.5 \mathrm{~Hz}$ $\mathrm{CH}=\mathrm{CH}), 7.20(7 \mathrm{H}, \mathrm{m}, 1 \mathrm{xCH}=\mathrm{CH}, 6 x \mathrm{ArH}), 6.83(1 \mathrm{H}, \mathrm{ddd}, J=7.7,2.4,1.6 \mathrm{~Hz}, \mathrm{ArH})$, $5.25\left(2 \mathrm{H}, \mathrm{s}, \mathrm{OCH}_{2} \mathrm{O}\right), 3.85\left(3 \mathrm{H}, \mathrm{s}, \mathrm{OCH}_{3}\right), 3.52\left(3 \mathrm{H}, \mathrm{s}, \mathrm{OCH}_{3}\right) . m / z 271\left(\mathrm{M}^{+}+1\right)$.

(E)-1-Methoxymethyloxy-4-(2-methoxy)styrylbenzene (3dx). Yield $=90 \% .{ }^{1} \mathrm{H}$ $\operatorname{NMR}\left(\mathrm{CDCl}_{3}\right) \delta 7.56(1 \mathrm{H}, \mathrm{dd}, J=7.8,1.6 \mathrm{~Hz}, \mathrm{ArH}), 7.46(2 \mathrm{H}, \mathrm{d}, J=8.5 \mathrm{~Hz}, \mathrm{H}-2, \mathrm{H}-$ 6), $7.39(1 \mathrm{H}, \mathrm{d}, J=16.6 \mathrm{~Hz}, \mathrm{CH}=\mathrm{CH}), 7.19(1 \mathrm{H}, \mathrm{dt}, J=7.8,1.6 \mathrm{~Hz}, \mathrm{ArH}), 7.04(4 \mathrm{H}$, m, $1 \times \mathrm{xCH}=\mathrm{CH}, 3 \times \mathrm{ArH}), 6.89(1 \mathrm{H}, \mathrm{d}, J=7.8 \mathrm{~Hz}, \mathrm{ArH}), 5.19\left(2 \mathrm{H}, \mathrm{s}, \mathrm{OCH}_{2} \mathrm{O}\right), 3.91$ $\left(3 \mathrm{H}, \mathrm{s}, \mathrm{OCH}_{3}\right), 3.48\left(3 \mathrm{H}, \mathrm{s}, \mathrm{OCH}_{3}\right) . m / z 271\left(\mathrm{M}^{+}+1\right), 239\left(\mathrm{M}^{+}-\mathrm{OMe}\right)$.

(E)-1-Methoxymethyloxy-3-(2-methoxy)styrylbenzene (3dy). Yield $=92 \% .{ }^{1} \mathrm{H}$ $\operatorname{NMR}\left(\mathrm{CDCl}_{3}\right) \delta 7.58(1 \mathrm{H}, \mathrm{dd}, J=7.8,1.6 \mathrm{~Hz}, \mathrm{ArH}), 7.50(1 \mathrm{H}, \mathrm{d}, J=16.9 \mathrm{~Hz}$, $\mathrm{CH}=\mathrm{CH}), 7.23(4 \mathrm{H}, \mathrm{m}, \mathrm{ArH}), 7.10(1 \mathrm{H}, \mathrm{d}, J=16.9 \mathrm{~Hz}, \mathrm{CH}=\mathrm{CH}), 6.91(3 \mathrm{H}, \mathrm{m}, \mathrm{ArH})$, $5.24\left(2 \mathrm{H}, \mathrm{s}, \mathrm{OCH}_{2} \mathrm{O}\right), 3.83\left(3 \mathrm{H}, \mathrm{s}, \mathrm{OCH}_{3}\right), 3.49\left(3 \mathrm{H}, \mathrm{s}, \mathrm{OCH}_{3}\right) . m / z 271\left(\mathrm{M}^{+}+1\right)$.

(E)-1-Methoxymethyloxy-2-(2-methoxy)styrylbenzene $(3 \mathrm{dz})$. Yield $=88 \%{ }^{1} \mathrm{H}$ $\operatorname{NMR}\left(\mathrm{CDCl}_{3}\right) \delta 7.68(1 \mathrm{H}, \mathrm{dd}, J=7.8,1.7 \mathrm{~Hz}, \mathrm{ArH}), 7.64(1 \mathrm{H}, \mathrm{dd}, J=7.8,1.6 \mathrm{~Hz}$ ArH), $7.48(2 \mathrm{H}, \mathrm{s}, \mathrm{CH}=\mathrm{CH}), 7.21(3 \mathrm{H}, \mathrm{m}, \mathrm{ArH}), 6.95(2 \mathrm{H}, \mathrm{m}, \mathrm{ArH}), 6.88(1 \mathrm{H}, \mathrm{d}, J=$ 
$\left.{ }^{\mathrm{S} 6} 7.8 \mathrm{~Hz}, \mathrm{ArH}\right), 5.20\left(2 \mathrm{H}, \mathrm{s}, \mathrm{OCH}_{2} \mathrm{O}\right), 3.88\left(3 \mathrm{H}, \mathrm{s}, \mathrm{OCH}_{3}\right), 3.51\left(3 \mathrm{H}, \mathrm{s}, \mathrm{OCH}_{3}\right) . \mathrm{m} / \mathrm{z}$ $271\left(\mathrm{M}^{+}+1\right), 239\left(\mathrm{M}^{+}-\mathrm{OMe}\right)$.

(E)-1-Methoxymethyloxy-4-(4-fluoro)styrylbenzene (3ex). Yield $=80 \% .{ }^{1} \mathrm{H}$ NMR $\left(\mathrm{CDCl}_{3}\right) \delta 7.43(4 \mathrm{H}, \mathrm{m}, 1 \times \mathrm{xCH}=\mathrm{CH}, 3 \times \mathrm{ArH}), 7.01(6 \mathrm{H}, 1 \times \mathrm{CH}=\mathrm{CH}, 5 \times \mathrm{ArH}), 5.22(2 \mathrm{H}$, $\left.\mathrm{s}, \mathrm{OCH}_{2} \mathrm{O}\right), 3.55\left(3 \mathrm{H}, \mathrm{s}, \mathrm{OCH}_{3}\right) . m / z 258\left(\mathrm{M}^{+}+1\right), 238\left(\mathrm{M}^{+}-\mathrm{F}\right), 227\left(\mathrm{M}^{+}-\mathrm{OMe}\right)$.

(E)-1-Methoxymethyloxy-3-(4-fluoro)styrylbenzene (3ey). Yield = 92\%. ${ }^{1} \mathrm{H}$ NMR $\left(\mathrm{CDCl}_{3}\right) \delta 7.56(2 \mathrm{H}, \mathrm{m}, \mathrm{ArH}), 7.10(8 \mathrm{H}, 2 \mathrm{xCH}=\mathrm{CH}, 6 x \mathrm{ArH}), 5.25\left(2 \mathrm{H}, \mathrm{s}, \mathrm{OCH}_{2} \mathrm{O}\right)$ $3.53\left(3 \mathrm{H}, \mathrm{s}, \mathrm{OCH}_{3}\right), m / z 258\left(\mathrm{M}^{+}+1\right), 238\left(\mathrm{M}^{+}-\mathrm{F}\right), 227\left(\mathrm{M}^{+}-\mathrm{OMe}\right)$.

(E)-1-Methoxymethyloxy-2-(4-fluoro)styrylbenzene (3ez). Yield = 89\%. ${ }^{1} \mathrm{H}$ NMR $\left(\mathrm{CDCl}_{3}\right) \delta 7.61(1 \mathrm{H}, \mathrm{d}, J=7.8 \mathrm{~Hz}, \mathrm{ArH}), 7.43(3 \mathrm{H}, \mathrm{m}, 1 \mathrm{xCH}=\mathrm{CH}, 2 \mathrm{xArH}), 7.15(5 \mathrm{H}$, $\mathrm{m}, 1 \mathrm{xCH}=\mathrm{CH}, 4 \mathrm{xArH}), 6.91(1 \mathrm{H}, \mathrm{d}, J=7.9 \mathrm{~Hz}, \mathrm{ArH}), 5.27\left(2 \mathrm{H}, \mathrm{s}, \mathrm{OCH} \mathrm{H}_{2} \mathrm{O}\right), 3.55$ $\left(3 \mathrm{H}, \mathrm{s}, \mathrm{OCH}_{3}\right) \cdot m / z 258\left(\mathrm{M}^{+}+1\right), 238\left(\mathrm{M}^{+}-\mathrm{F}\right), 227\left(\mathrm{M}^{+}-\mathrm{OMe}\right)$.

(E)-1-Methoxymethyloxy-4-(3-fluoro)styrylbenzene (3fx). Yield = 80\%. ${ }^{1} \mathrm{H}$ NMR $\left(\mathrm{CDCl}_{3}\right) \delta 7.46(2 \mathrm{H}, \mathrm{d}, J=8.6 \mathrm{~Hz}, \mathrm{H}-2, \mathrm{H}-6), 7.25(3 \mathrm{H}, \mathrm{m}, \mathrm{ArH}), 7.05(3 \mathrm{H}, \mathrm{m}$, $1 \times \mathrm{CH}=\mathrm{CH}, 2 \mathrm{xArH}), 6.96(2 \mathrm{H}, \mathrm{m}, 1 \mathrm{xCH}=\mathrm{CH}, 1 \times \mathrm{ArH}), 5.19\left(2 \mathrm{H}, \mathrm{s}, \mathrm{OCH}_{2} \mathrm{O}\right), 3.49$ $\left(3 \mathrm{H}, \mathrm{s}, \mathrm{OCH}_{3}\right) . m / z 258\left(\mathrm{M}^{+}+1\right), 227\left(\mathrm{M}^{+}-\mathrm{OMe}\right)$.

(E)-1-Methoxymethyloxy-3-(3-fluoro)styrylbenzene (3fy). Yield = 85\%. ${ }^{1} \mathrm{H}$ NMR $\left(\mathrm{CDCl}_{3}\right) \delta 7.23(7 \mathrm{H}, \mathrm{m}, 1 \times \mathrm{xCH}=\mathrm{CH}, 6 \times \mathrm{ArH}), 6.93(3 \mathrm{H}, \mathrm{m}, 1 \times \mathrm{CH}=\mathrm{CH}, 2 \mathrm{xArH}), 5.20$ $\left(2 \mathrm{H}, \mathrm{s}, \mathrm{OCH}_{2} \mathrm{O}\right), 3.49\left(3 \mathrm{H}, \mathrm{s}, \mathrm{OCH}_{3}\right) . m / z 258\left(\mathrm{M}^{+}+1\right), 227\left(\mathrm{M}^{+}-\mathrm{OMe}\right)$. 
${ }^{\text {S7}}(\mathbf{E})$-1-Methoxymethyloxy-2-(3-fluoro)styrylbenzene (3fz). Yield $=80 \% .{ }^{1} \mathrm{H}$ NMR $\left(\mathrm{CDCl}_{3}\right) \delta 7.61(1 \mathrm{H}, \mathrm{dd}, J=7.7,1.6 \mathrm{~Hz}, \mathrm{ArH}), 7.53(1 \mathrm{H}, \mathrm{d}, J=16.5 \mathrm{~Hz}, \mathrm{CH}=\mathrm{CH})$, $7.12(8 \mathrm{H}, \mathrm{m}, 1 \mathrm{xCH}=\mathrm{CH}, 7 \mathrm{xArH}), 5.25\left(2 \mathrm{H}, \mathrm{s}, \mathrm{OCH}_{2} \mathrm{O}\right), 3.50\left(3 \mathrm{H}, \mathrm{s}, \mathrm{OCH}_{3}\right) . m / z 258$ $\left(\mathrm{M}^{+}+1\right), 227\left(\mathrm{M}^{+}-\mathrm{OMe}\right)$.

(E)-1-Methoxymethyloxy-4-(2-fluoro)styrylbenzene (3gx). Yield $=90 \% .{ }^{1} \mathrm{H}$ NMR $\left(\mathrm{CDCl}_{3}\right) \delta 7.58(1 \mathrm{H}, \mathrm{dt}, J=7.7,1.8 \mathrm{~Hz}, \mathrm{ArH}), 7.48(2 \mathrm{H}, \mathrm{d}, J=8.8 \mathrm{~Hz}, \mathrm{H}-3, \mathrm{H}-5)$, $7.20(3 \mathrm{H}, \mathrm{m}, 1 \mathrm{xCH}=\mathrm{CH}, 2 \mathrm{xArH}), 7.04(3 \mathrm{H}, \mathrm{m}, 1 \mathrm{xCH}=\mathrm{CH}, 2 \mathrm{xArH}), 6.91(1 \mathrm{H}, \mathrm{m}$, ArH), $5.19\left(2 \mathrm{H}, \mathrm{s}, \mathrm{OCH}_{2} \mathrm{O}\right), 3.48\left(3 \mathrm{H}, \mathrm{s}, \mathrm{OCH}_{3}\right) . m / z 258\left(\mathrm{M}^{+}+1\right), 238\left(\mathrm{M}^{+}-\mathrm{F}\right), 227$ $\left(\mathrm{M}^{+}-\mathrm{OMe}\right)$.

(E)-1-Methoxymethyloxy-3-(2-fluoro)styrylbenzene (3gy). Yield = 96\%. ${ }^{1} \mathrm{H}$ NMR $\left(\mathrm{CDCl}_{3}\right) \delta 7.57(1 \mathrm{H}, \mathrm{dt}, J=7.7,1.7 \mathrm{~Hz}, \mathrm{ArH}), 7.21(6 \mathrm{H}, \mathrm{m}, 2 \mathrm{xCH}=\mathrm{CH}, 4 \times \mathrm{ArH}), 6.95$ $(3 \mathrm{H}, \mathrm{m}, \mathrm{ArH}), 5.20\left(2 \mathrm{H}, \mathrm{s}, \mathrm{OCH}_{2} \mathrm{O}\right), 3.49\left(3 \mathrm{H}, \mathrm{s}, \mathrm{OCH}_{3}\right) . \mathrm{m} / z 258\left(\mathrm{M}^{+}+1\right), 238\left(\mathrm{M}^{+}-\right.$ F), $227\left(\mathrm{M}^{+}-\mathrm{OMe}\right)$.

(E)-1-Methoxymethyloxy-2-(2-fluoro)styrylbenzene (3gz). Yield = 95\%. ${ }^{1} \mathrm{H}$ NMR $\left(\mathrm{CDCl}_{3}\right) \delta 7.65(1 \mathrm{H}, \mathrm{dt}, J=7.7,1.8 \mathrm{~Hz}, \mathrm{ArH}), 7.61(1 \mathrm{H}, \mathrm{d}, J=8.5 \mathrm{~Hz}, \mathrm{ArH}), 7.53$ $(1 \mathrm{H}, \mathrm{J}=8.8 \mathrm{~Hz}, \mathrm{ArH}), 7.17(4 \mathrm{H}, \mathrm{m}, 2 \mathrm{xCH}=\mathrm{CH}, 2 \mathrm{xArH}), 7.01(2 \mathrm{H}, \mathrm{m}, \mathrm{ArH}), 6.90$ $(1 \mathrm{H}, \mathrm{m}, \mathrm{ArH}), 5.24\left(2 \mathrm{H}, \mathrm{s}, \mathrm{OCH}_{2} \mathrm{O}\right), 3.50\left(3 \mathrm{H}, \mathrm{s}, \mathrm{OCH}_{3}\right) . \mathrm{m} / z 258\left(\mathrm{M}^{+}+1\right), 238\left(\mathrm{M}^{+}-\right.$ F), $227\left(\mathrm{M}^{+}\right.$- OMe $)$. 
${ }^{\mathbf{s 8}}(\mathbf{E})-1-M e t h o x y m e t h y l o x y-4-(3,5-d i f l u o r o)$ styrylbenzene $(3 \mathbf{h x})$. Yield $=97 \% .{ }^{1} \mathrm{H}$ NMR $\left(\mathrm{CDCl}_{3}\right) \delta 7.43(2 \mathrm{H}, \mathrm{d}, J=8.5 \mathrm{~Hz}, \mathrm{H}-3, \mathrm{H}-5), 6.88(7 \mathrm{H}, \mathrm{m}, 2 \mathrm{xCH}=\mathrm{CH}, 5 \mathrm{xArH})$, $5.18\left(2 \mathrm{H}, \mathrm{s}, \mathrm{OCH}_{2} \mathrm{O}\right), 3.47\left(3 \mathrm{H}, \mathrm{s}, \mathrm{OCH}_{3}\right) . \mathrm{m} / z 277\left(\mathrm{M}^{+}+1\right), 257\left(\mathrm{M}^{+}-\mathrm{F}\right), 245\left(\mathrm{M}^{+}-\right.$ $\mathrm{OMe}$ ).

(E)-1-Methoxymethyloxy-3-(3,5-difluoro)styrylbenzene (3hy). Yield $=91 \% .{ }^{1} \mathrm{H}$ NMR $\left(\mathrm{CDCl}_{3}\right) \delta 6.85(9 \mathrm{H}, \mathrm{m}, 2 \mathrm{xCH}=\mathrm{CH}, 7 \mathrm{xArH}), 5.20\left(2 \mathrm{H}, \mathrm{s}, \mathrm{OCH}_{2} \mathrm{O}\right), 3.50(3 \mathrm{H}, \mathrm{s}$, $\left.\mathrm{OCH}_{3}\right) \cdot m / z 277\left(\mathrm{M}^{+}+1\right), 257\left(\mathrm{M}^{+}-\mathrm{F}\right), 245\left(\mathrm{M}^{+}-\mathrm{OMe}\right)$.

(E)-1-Methoxymethyloxy-2-(3,5-difluoro)styrylbenzene $(\mathbf{3 h z})$. Yield $=92 \% .{ }^{1} \mathrm{H}$ NMR $\left(\mathrm{CDCl}_{3}\right) \delta 7.64(1 \mathrm{H}, \mathrm{d}, J=8.5 \mathrm{~Hz}, \mathrm{ArH}), 7.53(1 \mathrm{H}, \mathrm{d}, J=16.4 \mathrm{~Hz}, \mathrm{CH}=\mathrm{CH})$, $7.50(1 \mathrm{H}, \mathrm{d}, J=16.4 \mathrm{~Hz}, \mathrm{CH}=\mathrm{CH}), 6.91(6 \mathrm{H}, \mathrm{m}, \mathrm{ArH}), 5.19\left(2 \mathrm{H}, \mathrm{s}, \mathrm{OCH}_{2} \mathrm{O}\right), 3.51$ $\left(3 \mathrm{H}, \mathrm{s}, \mathrm{OCH}_{3}\right) . m / z 257\left(\mathrm{M}^{+}-\mathrm{F}\right), 245\left(\mathrm{M}^{+}-\mathrm{OMe}\right)$.

(E)-1-Methoxymethyloxy-4-(3,4-difluoro)styrylbenzene (3ix). Yield $=74 \% .{ }^{1} \mathrm{H}$ NMR $\left(\mathrm{CDCl}_{3}\right) \delta 7.69(2 \mathrm{H}, \mathrm{dd}, J=8.7,2.3 \mathrm{~Hz}, \mathrm{ArH}), 7.44(3 \mathrm{H}, \mathrm{m}, 1 \mathrm{xCH}=\mathrm{CH}$, 2xArH), 7.31 (2H, dd, J = 8.6, 2.6 Hz, ArH), 7.17 (2H, m, 1xCH=CH, 1xArH), 5.44 $\left(2 \mathrm{H}, \mathrm{s}, \mathrm{OCH}_{2} \mathrm{O}\right), 3.74\left(3 \mathrm{H}, \mathrm{s}, \mathrm{OCH}_{3}\right) \cdot \mathrm{m} / \mathrm{z}, 277\left(\mathrm{M}^{+}+1\right), 257\left(\mathrm{M}^{+}-\mathrm{F}\right), 245\left(\mathrm{M}^{+}-\right.$ OMe).

(E)-1-Methoxymethyloxy-3-(3,4-difluoro)styrylbenzene (3iy). Yield $=76 \% .{ }^{1} \mathrm{H}$ $\operatorname{NMR}\left(\mathrm{CDCl}_{3}\right) \delta 7.13(9 \mathrm{H}, \mathrm{m}, 2 \mathrm{xCH}=\mathrm{CH}, 7 \mathrm{xArH}), 5.25\left(2 \mathrm{H}, \mathrm{s}, \mathrm{OCH}_{2} \mathrm{O}\right), 3.54(3 \mathrm{H}, \mathrm{s}$, $\left.\mathrm{OCH}_{3}\right) \cdot m / z 277\left(\mathrm{M}^{+}+1\right), 257\left(\mathrm{M}^{+}-\mathrm{F}\right), 245\left(\mathrm{M}^{+}-\mathrm{OMe}\right)$. 
${ }^{\text {S9}}$ (E)-1-Methoxymethyloxy-2-(3,4-difluoro)styrylbenzene (3iz). Yield $=45 \% .{ }^{1} \mathrm{H}$ NMR $\left(\mathrm{CDCl}_{3}\right) \delta 7.62(1 \mathrm{H}, \mathrm{d}, J=8.5 \mathrm{~Hz}, \mathrm{ArH}), 7.18(8 \mathrm{H}, \mathrm{m}, 2 \mathrm{xCH}=\mathrm{CH}, 6 x \mathrm{ArH})$, $5.24\left(2 \mathrm{H}, \mathrm{s}, \mathrm{OCH}_{2} \mathrm{O}\right), 3.51\left(3 \mathrm{H}, \mathrm{s}, \mathrm{OCH}_{3}\right) . \mathrm{m} / z 277\left(\mathrm{M}^{+}+1\right), 257\left(\mathrm{M}^{+}-\mathrm{F}\right), 245\left(\mathrm{M}^{+}-\right.$ OMe).

(E)-1-Methoxymethyloxy-4-(3,5-dimethoxy)styrylbenzene $(\mathbf{3 j x})$. Yield $=87 \% .{ }^{1} \mathrm{H}$ $\operatorname{NMR}\left(\mathrm{CDCl}_{3}\right) \delta 7.49(2 \mathrm{H}, \mathrm{d}, J=8.7 \mathrm{~Hz}, \mathrm{H}-3, \mathrm{H}-5), 7.04(3 \mathrm{H}, \mathrm{m}, 1 \mathrm{xCH}=\mathrm{CH}, 2 \mathrm{xArH})$, $6.98(1 \mathrm{H}, \mathrm{d}, J=16.4 \mathrm{~Hz}, \mathrm{CH}=\mathrm{CH}), 6.69(2 \mathrm{H}, \mathrm{d}, J=7.6 \mathrm{~Hz}, \mathrm{ArH}), 6.42(1 \mathrm{H}, \mathrm{t}, J=7.6$ $\mathrm{Hz}, \mathrm{ArH}), 5.29\left(2 \mathrm{H}, \mathrm{s}, \mathrm{OCH}_{2} \mathrm{O}\right), 3.87\left(6 \mathrm{H}, \mathrm{s}, 2 \mathrm{xOCH}_{3}\right), 3.53\left(3 \mathrm{H}, \mathrm{s}, \mathrm{OCH}_{3}\right) . \mathrm{m} / z 301$ $\left(\mathrm{M}^{+}+1\right)$

(E)-1-Methoxymethyloxy-3-(3,5-dimethoxy)styrylbenzene $(\mathbf{3 j y})$. Yield $=97 \% .{ }^{1} \mathrm{H}$ NMR $\left(\mathrm{CDCl}_{3}\right) \delta 7.16(6 \mathrm{H}, \mathrm{m}, 2 \mathrm{xCH}=\mathrm{CH}, 4 \mathrm{xArH}), 6.94(2 \mathrm{H}, \mathrm{d}, J=2.2 \mathrm{~Hz}, \mathrm{ArH}), 6.61$ $\left.(1 \mathrm{H}, \mathrm{t}, J=2.2 \mathrm{~Hz}, \mathrm{ArH}), 5.25\left(2 \mathrm{H}, \mathrm{s}, \mathrm{OCH}_{2} \mathrm{O}\right), 3.81(6 \mathrm{H}, \mathrm{s}, 2 \mathrm{xOCH})_{3}\right), 3.51(3 \mathrm{H}, \mathrm{s}$, $\left.\mathrm{OCH}_{3}\right) \cdot m / z 301\left(\mathrm{M}^{+}+1\right)$.

(E)-1-Methoxymethyloxy-2-(3,5-dimethoxy)styrylbenzene $(\mathbf{3 j z})$. Yield $=92 \% .{ }^{1} \mathrm{H}$ $\operatorname{NMR}\left(\mathrm{CDCl}_{3}\right) \delta 7.66(1 \mathrm{H}, \mathrm{dd}, J=7.7,1.5 \mathrm{~Hz}, \mathrm{ArH}), 7.54(1 \mathrm{H}, \mathrm{d}, J=16.5 \mathrm{~Hz}$ $\mathrm{CH}=\mathrm{CH}), 7.18(4 \mathrm{H}, \mathrm{m}, 1 \mathrm{xCH}=\mathrm{CH}, 3 \mathrm{xArH}), 6.74(2 \mathrm{H}, \mathrm{d}, J=2.3 \mathrm{~Hz}, \mathrm{ArH}), 6.43(1 \mathrm{H}$, $\mathrm{t}, J=2.3 \mathrm{~Hz}, \mathrm{ArH}), 5.29\left(2 \mathrm{H}, \mathrm{s}, \mathrm{OCH}_{2} \mathrm{O}\right), 3.88\left(6 \mathrm{H}, \mathrm{s}, 2 \mathrm{xOCH}_{3}\right), 3.51\left(3 \mathrm{H}, \mathrm{s}, \mathrm{OCH}_{3}\right)$. $m / z 301\left(\mathrm{M}^{+}+1\right), 269\left(\mathrm{M}^{+}-\mathrm{OMe}\right)$.

General method for synthesis of hydroxylated (E)-stilbenes 
${ }^{\mathrm{S} 10}$ Substituted hydroxylated (E)-stilbene methoxy methyl ether (3ax-jz) $(5 \mathrm{mmol})$ was dissolved in methanol (40 mL). Pyridinium $p$-toluenesulfonate $(50 \mathrm{mmol})$ was added, and the mixture was heated to reflux until completion of the reaction (monitored by TLC, eluant $\mathrm{CHCl}_{3}$ ). The solvent was then evaporated in vacuo and the white residue dissolved in brine $(40 \mathrm{~mL})$ and extracted with diethyl ether $(3 \times 25 \mathrm{~mL})$. The organic layers were collected, washed with water $(3 \times 25 \mathrm{~mL})$, dried over $\mathrm{MgSO}_{4}$ and evaporated. The collected products were recrystallised from $\mathrm{MeOH} /$ water to afford the pure substituted hydroxylated (E)-stilbenes.

(E)-1-hydroxy-4-styrylbenzene (5ax). Commercially available (Sigma-Aldrich, U.K.).

(E)-1-hydroxy-3-styrylbenzene (5ay). White solid. Yield $=95 \% . \mathrm{mp}=119-120^{\circ} \mathrm{C}$. ${ }^{1} \mathrm{H} \mathrm{NMR}\left(\mathrm{CDCl}_{3}\right) \delta 7.51(2 \mathrm{H}, \mathrm{d}, J=7.3 \mathrm{~Hz}, \mathrm{ArH}), 7.38(4 \mathrm{H}, \mathrm{m}, 1 \mathrm{xCH}=\mathrm{CH}, 3 \mathrm{xArH})$, $7.19(4 \mathrm{H}, \mathrm{m}, 1 \mathrm{xCH} H \mathrm{CH}, 3 \mathrm{xArH}), 6.74(1 \mathrm{H}, \mathrm{d}, J=7.4 \mathrm{~Hz}, \mathrm{ArH}), 5.00(1 \mathrm{H}, \mathrm{s}, \mathrm{ArOH})$. $m / z 197\left(\mathrm{M}^{+}+1\right)$. Anal. $\left(\mathrm{C}_{14} \mathrm{H}_{12} \mathrm{O}\right) \mathrm{C}, \mathrm{H}$.

(E)-1-hydroxy-2-styrylbenzene (5az). Grey crystals. Yield $=90 \% . \mathrm{mp}=139-140^{\circ} \mathrm{C}$. ${ }^{1} \mathrm{H} \mathrm{NMR}\left(\mathrm{CDCl}_{3}\right) \delta 7.54(3 \mathrm{H}, \mathrm{d}, J=7.3 \mathrm{~Hz}, \mathrm{ArH}), 7.35(3 \mathrm{H}, \mathrm{m}, 1 \mathrm{xCH}=\mathrm{CH}, 2 \mathrm{xArH})$, $7.14(3 \mathrm{H}, \mathrm{m}, 1 \times \mathrm{xCH}=\mathrm{CH}, 2 \mathrm{xArH}), 6.94(1 \mathrm{H}, \mathrm{t}, J=7.5 \mathrm{~Hz}, \mathrm{ArH}), 6.81(1 \mathrm{H}, \mathrm{d}, J=7.5$ $\mathrm{Hz}, \operatorname{ArH}), 5.60(1 \mathrm{H}, \mathrm{s}, \mathrm{ArOH}) . m / z 197\left(\mathrm{M}^{+}+1\right)$. Anal. $\left(\mathrm{C}_{14} \mathrm{H}_{12} \mathrm{O}\right) \mathrm{C}, \mathrm{H}$.

(E)-1-hydroxy-4-(4-methoxy)styrylbenzene (5bx). Pale rose solid. Yield =79\%. $\mathrm{mp}$ $=207-208^{\circ} \mathrm{C} .{ }^{1} \mathrm{H} \mathrm{NMR}\left(\mathrm{CDCl}_{3}\right) \delta 9.54(1 \mathrm{H}, \mathrm{s}, \mathrm{ArOH}), 7.50(2 \mathrm{H}, \mathrm{d}, J=8.7 \mathrm{~Hz}, \mathrm{ArH})$, 
${ }^{\mathrm{S} 11} 7.41(2 \mathrm{H}, \mathrm{d}, J=8.5 \mathrm{~Hz}, \mathrm{ArH}), 6.98(2 \mathrm{H}, \mathrm{s}, 2 \mathrm{xCH}=\mathrm{CH}), 6.95(2 \mathrm{H}, \mathrm{d}, J=8.7 \mathrm{~Hz}$, $\operatorname{ArH}), 6.78(2 \mathrm{H}, \mathrm{d}, J=8.5 \mathrm{~Hz}, \mathrm{ArH}), 3.77\left(3 \mathrm{H}, \mathrm{s}, \mathrm{OCH}_{3}\right) . m / z 227\left(\mathrm{M}^{+}+1\right)$. Anal. $\left(\mathrm{C}_{15} \mathrm{H}_{14} \mathrm{O}_{2}\right) \mathrm{C}, \mathrm{H}$.

(E)-1-hydroxy-3-(4-methoxy)styrylbenzene (5by). Pale yellow solid. Yield $=74 \%$. $\mathrm{mp}=159-160^{\circ} \mathrm{C} .{ }^{1} \mathrm{H}$ NMR $\left(\mathrm{CD}_{3} \mathrm{OD}\right) \delta 7.47(2 \mathrm{H}, \mathrm{d}, J=8.7 \mathrm{~Hz}, \mathrm{H}-2, \mathrm{H}-6), 7.02(7 \mathrm{H}$, m, 2xCH=CH, 5xArH), $6.66(1 \mathrm{H}, \mathrm{dd}, J=7.9,1.6 \mathrm{~Hz}, \mathrm{ArH}), 3.83\left(3 \mathrm{H}, \mathrm{s}, \mathrm{OCH}_{3}\right) . \mathrm{m} / z$ $227\left(\mathrm{M}^{+}+1\right)$. Anal. $\left(\mathrm{C}_{15} \mathrm{H}_{14} \mathrm{O}_{2}\right) \mathrm{C}, \mathrm{H}$.

(E)-1-hydroxy-2-(4-methoxy)styrylbenzene (5bz). Pale brown solid. Yield = 33\%. $\mathrm{mp}=117-118^{\circ} \mathrm{C} .{ }^{1} \mathrm{H}$ NMR $\left(\mathrm{CD}_{3} \mathrm{OD}\right) \delta 7.51(1 \mathrm{H}, \mathrm{d}, J=7.8 \mathrm{~Hz}, \mathrm{ArH}), 7.46(2 \mathrm{H}, \mathrm{d}, J=$ $8.8 \mathrm{~Hz}, \mathrm{H}-2, \mathrm{H}-6), 7.35(1 \mathrm{H}, \mathrm{d}, J=16.4 \mathrm{~Hz}, \mathrm{CH}=\mathrm{CH}), 7.09(2 \mathrm{H}, \mathrm{m}, 1 \mathrm{xCH}=\mathrm{CH}$, 1xArH), 6.83 (4H, m, ArH), $3.79\left(3 \mathrm{H}, \mathrm{s}, \mathrm{OCH}_{3}\right) . m / z 227\left(\mathrm{M}^{+}+1\right)$. Anal. $\left(\mathrm{C}_{15} \mathrm{H}_{14} \mathrm{O}_{2}\right)$ C, H.

(E)-1-hydroxy-4-(3-methoxy)styrylbenzene (5cx). White solid. Yield = 92\%. $\mathrm{mp}=$ 118-119 ${ }^{\circ} \mathrm{C} .{ }^{1} \mathrm{H}$ NMR $\left(\mathrm{CD}_{3} \mathrm{OD}\right) \delta 7.41(2 \mathrm{H}, \mathrm{d}, J=8.6 \mathrm{~Hz}, \mathrm{H}-3, \mathrm{H}-5), 7.23(1 \mathrm{H}, \mathrm{t}, J=$ $7.9 \mathrm{~Hz}, \mathrm{ArH}), 7.08(3 \mathrm{H}, \mathrm{m}, 1 \mathrm{xCH}=\mathrm{CH}, 2 \mathrm{xArH}), 6.96(1 \mathrm{H}, \mathrm{d}, J=16.5 \mathrm{~Hz}, \mathrm{CH}=\mathrm{CH})$, $6.82(3 \mathrm{H}, \mathrm{m}, \mathrm{ArH}), 3.83\left(3 \mathrm{H}, \mathrm{s}, \mathrm{OCH}_{3}\right) . m / z 227\left(\mathrm{M}^{+}+1\right)$. Anal. $\left(\mathrm{C}_{15} \mathrm{H}_{14} \mathrm{O}_{2}\right) \mathrm{C}, \mathrm{H}$.

(E)-1-hydroxy-3-(3-methoxy)styrylbenzene (5cy). White solid. Yield $=83 \% . \mathrm{mp}=$ 74-75 ${ }^{\circ} \mathrm{C} .{ }^{1} \mathrm{H}$ NMR $\left(\mathrm{CD}_{3} \mathrm{OD}\right) \delta 7.12(8 \mathrm{H}, \mathrm{m}, 2 \mathrm{xCH}=\mathrm{CH}, 6 \mathrm{xArH}), 6.79(1 \mathrm{H}, \mathrm{d}, J=8.2$ $\mathrm{Hz}, \mathrm{ArH}), 6.70(1 \mathrm{H}, \mathrm{d}, J=8.0 \mathrm{~Hz}, \mathrm{ArH}), 3.82\left(3 \mathrm{H}, \mathrm{s}, \mathrm{OCH}_{3}\right) . m / z 227\left(\mathrm{M}^{+}+1\right)$. Anal. $\left(\mathrm{C}_{15} \mathrm{H}_{14} \mathrm{O}_{2}\right) \mathrm{C}, \mathrm{H}$. 
${ }^{\text {S12 }}$ (E)-1-hydroxy-2-(3-methoxy)styrylbenzene $\mathbf{( 5 c z )}$. Pale yellow solid. Yield = 79\%. $\mathrm{mp}=89-90^{\circ} \mathrm{C} .{ }^{1} \mathrm{H}$ NMR $\left(\mathrm{CD}_{3} \mathrm{OD}\right) \delta 7.52(2 \mathrm{H}, \mathrm{m}, 1 \mathrm{xCH}=\mathrm{CH}, 1 \mathrm{xArH}), 7.14$ (5H, m, 1xCH=CH, 4xArH), $6.85(3 \mathrm{H}, \mathrm{m}, \mathrm{ArH}), 3.84\left(3 \mathrm{H}, \mathrm{s}, \mathrm{OCH}_{3}\right) . \mathrm{m} / 2227\left(\mathrm{M}^{+}+\right.$ 1). Anal. $\left(\mathrm{C}_{15} \mathrm{H}_{14} \mathrm{O}_{2}\right) \mathrm{C}, \mathrm{H}$.

(E)-1-hydroxy-4-(2-methoxy)styrylbenzene (5dx). White solid. Yield $=88 \% \cdot \mathrm{mp}=$ 145-146 ${ }^{\circ}$. ${ }^{1} \mathrm{H}$ NMR $\left(\mathrm{CD}_{3} \mathrm{OD}\right) \delta 7.54(2 \mathrm{H}, \mathrm{d}, J=8.0 \mathrm{~Hz}, \mathrm{H}-3, \mathrm{H}-5), 7.28(3 \mathrm{H}, \mathrm{m}$, 1xCH=CH, 2xArH), $6.96(3 \mathrm{H}, \mathrm{m}, 1 \mathrm{xCH}=\mathrm{CH}, 2 \mathrm{xArH}), 6.75(2 \mathrm{H}, \mathrm{d}, J=8.0 \mathrm{~Hz}, \mathrm{H}-2$, H-6), $3.87\left(3 \mathrm{H}, \mathrm{s}, \mathrm{OCH}_{3}\right) . m / z 227\left(\mathrm{M}^{+}+1\right)$. Anal. $\left(\mathrm{C}_{15} \mathrm{H}_{14} \mathrm{O}_{2}\right) \mathrm{C}, \mathrm{H}$.

(E)-1-hydroxy-3-(2-methoxy)styrylbenzene (5dy). White solid. Yield $=82 \% . \mathrm{mp}=$ 78-79 ${ }^{\circ} \mathrm{C} .{ }^{1} \mathrm{H}$ NMR $\left(\mathrm{CD}_{3} \mathrm{OD}\right) \delta 7.64(1 \mathrm{H}, \mathrm{d}, J=7.6 \mathrm{~Hz}, \mathrm{ArH}), 7.49(1 \mathrm{H}, \mathrm{d}, J=16.5$ $\mathrm{Hz}, \mathrm{CH}=\mathrm{CH}), 7.27-6.97(7 \mathrm{H}, \mathrm{m}, 1 \mathrm{xCH}=\mathrm{CH}, 6 \mathrm{xArH}), 6.85(1 \mathrm{H}, \mathrm{d}, J=7.7 \mathrm{~Hz}, \mathrm{ArH})$, $3.88\left(3 \mathrm{H}, \mathrm{s}, \mathrm{OCH}_{3}\right) . m / z 227\left(\mathrm{M}^{+}+1\right)$. Anal. $\left(\mathrm{C}_{15} \mathrm{H}_{14} \mathrm{O}_{2}\right) \mathrm{C}, \mathrm{H}$.

(E)-1-hydroxy-2-(2-methoxy)styrylbenzene (5dz). Yellow solid. Yield = 85\%. $\mathrm{mp}=$ 105-106 ${ }^{\circ} \mathrm{C} .{ }^{1} \mathrm{H}$ NMR $\left(\mathrm{CD}_{3} \mathrm{OD}\right) \delta 7.64(1 \mathrm{H}, \mathrm{dd}, J=7.6,1.6 \mathrm{~Hz}, \mathrm{ArH}), 7.56(1 \mathrm{H}, \mathrm{dd}, J$ $=7.7,1.6, \mathrm{ArH}), 7.50(1 \mathrm{H}, \mathrm{d}, J=16.5 \mathrm{~Hz}, \mathrm{CH}=\mathrm{CH}), 7.37(1 \mathrm{H}, \mathrm{d}, J=16.5 \mathrm{~Hz}$, $\mathrm{CH}=\mathrm{CH}), 7.26(1 \mathrm{H}, \mathrm{dt}, J=7.7,1.6 \mathrm{~Hz}, \mathrm{ArH}), 7.14(1 \mathrm{H}, \mathrm{dt}, J=7.7,1.6 \mathrm{~Hz}, \mathrm{ArH})$, $6.95(3 \mathrm{H}, \mathrm{m}, \mathrm{ArH}), 6.83(1 \mathrm{H}, \mathrm{dd}, J=7.8,1.6 \mathrm{~Hz}, \mathrm{ArH}), 3.87\left(3 \mathrm{H}, \mathrm{s}, \mathrm{OCH}_{3}\right) . m / z 227$ $\left(\mathrm{M}^{+}+1\right)$. Anal. $\left(\mathrm{C}_{15} \mathrm{H}_{14} \mathrm{O}_{2}\right) \mathrm{C}, \mathrm{H}$. 
${ }^{\mathbf{S 1 3}}$ (E)-1-hydroxy-4-(4-fluoro)styrylbenzene (5ex). White solid. Yield $=93 \% . \mathrm{mp}=$ 179-180 ${ }^{\circ} \mathrm{C} .{ }^{1} \mathrm{H}$ NMR $\left(d_{6}\right.$-DMSO) $\delta 9.40(1 \mathrm{H}, \mathrm{s}, \mathrm{ArOH}), 7.38(4 \mathrm{H}, \mathrm{m}, \mathrm{ArH}), 6.85(4 \mathrm{H}$, m, $2 \mathrm{xCH}=\mathrm{CH}, 2 \mathrm{xArH}), 6.58(2 \mathrm{H}, \mathrm{d}, J=7.8 \mathrm{~Hz}, \mathrm{ArH}) . m / z 215\left(\mathrm{M}^{+}+1\right)$. Anal. $\left(\mathrm{C}_{14} \mathrm{H}_{11} \mathrm{FO}\right) \mathrm{C}, \mathrm{H}$.

(E)-1-hydroxy-3-(4-fluoro)styrylbenzene (5ey). White solid. Yield $=95 \% \cdot \mathrm{mp}=$ 114-115 ${ }^{\circ} \mathrm{C} .{ }^{1} \mathrm{H}$ NMR $\left(\mathrm{CDCl}_{3}\right) \delta 7.49(2 \mathrm{H}, \mathrm{m}, \mathrm{ArH}), 7.26(1 \mathrm{H}, \mathrm{m}, \mathrm{ArH}), 7.08(6 \mathrm{H}, \mathrm{m}$, 2xCH=CH, 4xArH), $6.76(1 \mathrm{H}, \mathrm{dd}, J=7.7,1.6 \mathrm{~Hz}, \mathrm{ArH}), 4.72(1 \mathrm{H}, \mathrm{s}, \mathrm{ArOH}) . m / z 215$ $\left(\mathrm{M}^{+}+1\right)$. Anal. $\left(\mathrm{C}_{14} \mathrm{H}_{11} \mathrm{FO}\right) \mathrm{C}, \mathrm{H}$.

(E)-1-hydroxy-2-(4-fluoro)styrylbenzene (5ez). Yellow solid. Yield $=72 \% . \mathrm{mp}=$ 92-93 ${ }^{\circ} \mathrm{C} .{ }^{1} \mathrm{H}$ NMR $\left(d_{6}\right.$-DMSO) $\delta 9.67(1 \mathrm{H}, \mathrm{s}, \mathrm{ArOH}), 7.28(10 \mathrm{H}, \mathrm{m}, 2 \mathrm{xCH}=\mathrm{CH}$, 8xArH). $m / z, 215\left(\mathrm{M}^{+}+1\right)$. Anal. $\left(\mathrm{C}_{14} \mathrm{H}_{11} \mathrm{FO}\right) \mathrm{C}, \mathrm{H}$.

(E)-1-hydroxy-4-(3-fluoro)styrylbenzene (5fx). White solid. Yield $=90 \% \cdot \mathrm{mp}=$ 151-152 ${ }^{\circ} \mathrm{C} .{ }^{1} \mathrm{H}$ NMR $\left(\mathrm{CDCl}_{3}\right) \delta 7.42(2 \mathrm{H}, \mathrm{d}, J=8.4 \mathrm{~Hz}, \mathrm{H}-3, \mathrm{H}-5), 7.38(8 \mathrm{H}, \mathrm{m}$, 2xCH=CH, 6xArH), $4.93(1 \mathrm{H}, \mathrm{s}, \mathrm{ArOH}) . m / z 215\left(\mathrm{M}^{+}+1\right)$. Anal. $\left(\mathrm{C}_{14} \mathrm{H}_{11} \mathrm{FO}\right) \mathrm{C}, \mathrm{H}$.

(E)-1-hydroxy-3-(3-fluoro)styrylbenzene (5fy). White solid. Yield $=83 \% \cdot \mathrm{mp}=$ $100-101{ }^{\circ} \mathrm{C} .{ }^{1} \mathrm{H}$ NMR $\left(\mathrm{CDCl}_{3}\right) \delta 7.19(9 \mathrm{H}, \mathrm{m}, 2 \mathrm{xCH}=\mathrm{CH}, 7 \mathrm{xArH}), 6.86(1 \mathrm{H}, \mathrm{dd}, J=$ 7.6, 1.5 Hz, ArH), 5.24 (1H, bs, ArOH). m/z $215\left(\mathrm{M}^{+}+1\right)$. Anal. $\left(\mathrm{C}_{14} \mathrm{H}_{11} \mathrm{FO}\right) \mathrm{C}, \mathrm{H}$.

(E)-1-hydroxy-2-(3-fluoro)styrylbenzene (5fz). Grey solid. Yield = 96\%. $\mathrm{mp}=93$ $94^{\circ} \mathrm{C} .{ }^{1} \mathrm{H}$ NMR $\left(\mathrm{CDCl}_{3}\right) \delta 7.58(1 \mathrm{H}, \mathrm{dd}, J=7.7,1.6 \mathrm{~Hz}, \mathrm{ArH}), 7.47(1 \mathrm{H}, \mathrm{d}, J=16.3$ 
$\left.{ }^{\mathrm{S} 14} \mathrm{~Hz}, \mathrm{CH}=\mathrm{CH}\right), 7.30(4 \mathrm{H}, \mathrm{m}, \mathrm{ArH}), 7.16(1 \mathrm{H}, \mathrm{d}, J=16.3 \mathrm{~Hz}, \mathrm{CH}=\mathrm{CH}), 6.99(2 \mathrm{H}, \mathrm{m}$, ArH), $6.85(1 \mathrm{H}, \mathrm{d}, J=7.6 \mathrm{~Hz}, \mathrm{ArH}) . m / z 215\left(\mathrm{M}^{+}+1\right)$. Anal. $\left(\mathrm{C}_{14} \mathrm{H}_{11} \mathrm{FO}\right) \mathrm{C}, \mathrm{H}$.

(E)-1-hydroxy-4-(2-fluoro)styrylbenzene (5gx). White solid. Yield $=95 \% . \mathrm{mp}=$ 147-148 ${ }^{\circ} \mathrm{C} .{ }^{1} \mathrm{H}$ NMR $\left(\mathrm{CD}_{3} \mathrm{OD}\right) \delta 7.62(1 \mathrm{H}, \mathrm{dt}, J=7.7,1.6 \mathrm{~Hz}, \mathrm{ArH}), 7.40(2 \mathrm{H}, \mathrm{d}, J=$ $8.6 \mathrm{~Hz}, \mathrm{H}-3, \mathrm{H}-5), 7.10(5 \mathrm{H}, \mathrm{m}, 2 \mathrm{xCH}=\mathrm{CH}, 3 \times \mathrm{ArH}), 6.81(2 \mathrm{H}, \mathrm{d}, J=8.6 \mathrm{~Hz}, \mathrm{H}-2, \mathrm{H}-$ 6). $m / z 215\left(\mathrm{M}^{+}+1\right)$. Anal. $\left(\mathrm{C}_{14} \mathrm{H}_{11} \mathrm{FO}\right) \mathrm{C}, \mathrm{H}$.

(E)-1-hydroxy-3-(2-fluoro)styrylbenzene (5gy). White solid. Yield =96\%. $\mathrm{mp}=94$ $95^{\circ} \mathrm{C} .{ }^{1} \mathrm{H}$ NMR $\left(\mathrm{CD}_{3} \mathrm{OD}\right) \delta 7.66(1 \mathrm{H}, \mathrm{dt}, J=7.6,1.5 \mathrm{~Hz}, \mathrm{ArH}), 7.12(8 \mathrm{H}, \mathrm{m}$, 2xCH=CH, 6xArH), $6.76(1 \mathrm{H}, \mathrm{dd}, J=7.7,1.5 \mathrm{~Hz}, \mathrm{ArH}) . m / z 215\left(\mathrm{M}^{+}+1\right)$. Anal. $\left(\mathrm{C}_{14} \mathrm{H}_{11} \mathrm{FO}\right) \mathrm{C}, \mathrm{H}$.

(E)-1-hydroxy-2-(2-fluoro)styrylbenzene (5gz). White solid. Yield $=89 \% . \mathrm{mp}=$ $120-121^{\circ} \mathrm{C} .{ }^{1} \mathrm{H}$ NMR $\left(\mathrm{CD}_{3} \mathrm{OD}\right) \delta 7.63(1 \mathrm{H}, \mathrm{dt}, J=7.7,1.6 \mathrm{~Hz}, \mathrm{ArH}), 7.58(1 \mathrm{H}, \mathrm{m}$, ArH), $7.47(1 \mathrm{H}, \mathrm{d}, J=16.5 \mathrm{~Hz}, \mathrm{CH}=\mathrm{CH}), 7.03(7 \mathrm{H}, \mathrm{m}, 1 \mathrm{xCH} H \mathrm{CH}, 6 \mathrm{xArH}) . m / z 215$ $\left(\mathrm{M}^{+}+1\right)$. Anal. $\left(\mathrm{C}_{14} \mathrm{H}_{11} \mathrm{FO}\right) \mathrm{C}, \mathrm{H}$.

(E)-1-hydroxy-4-(3,5-difluoro)styrylbenzene (5hx). White solid. Yield = 95\%. $\mathrm{mp}$ $=141-142^{\circ} \mathrm{C} .{ }^{1} \mathrm{H}$ NMR $\left(d_{6}\right.$-DMSO) $\delta 9.72(1 \mathrm{H}, \mathrm{s}, \mathrm{ArOH}), 7.47(2 \mathrm{H}, \mathrm{d}, J=8.6 \mathrm{~Hz}, \mathrm{H}-$ 3, H-5), 7.14 (5H, m, 2xCH=CH, 3xArH), $6.82(2 \mathrm{H}, \mathrm{d}, J=8.6 \mathrm{~Hz}, \mathrm{H}-2, \mathrm{H}-6) . m / z 233$ $\left(\mathrm{M}^{+}+1\right)$. Anal. $\left(\mathrm{C}_{14} \mathrm{H}_{10} \mathrm{~F}_{2} \mathrm{O}\right) \mathrm{C}, \mathrm{H}$. 
${ }^{\text {S15}}$ (E)-1-hydroxy-3-(3,5-difluoro)styrylbenzene (5hy). White solid. Yield $=43 \%$. $\mathrm{mp}=96-97^{\circ} \mathrm{C} .{ }^{1} \mathrm{H} \mathrm{NMR}\left(\mathrm{CDCl}_{3}\right) 7.25(1 \mathrm{H}, \mathrm{t}, J=7.6 \mathrm{~Hz}, \mathrm{ArH}), 6.85(8 \mathrm{H}, \mathrm{m}$, 2xCH=CH, 6xArH), $4.84(1 \mathrm{H}, \mathrm{s}, \mathrm{ArOH}) . m / z 233\left(\mathrm{M}^{+}+1\right)$. Anal. $\left(\mathrm{C}_{14} \mathrm{H}_{10} \mathrm{~F}_{2} \mathrm{O}\right) \mathrm{C}, \mathrm{H}$.

(E)-1-hydroxy-2-(3,5-difluoro)styrylbenzene (5hz). White solid. Yield = 36\%. $\mathrm{mp}=$ 99-100 ${ }^{\circ} \mathrm{C} .{ }^{1} \mathrm{H}$ NMR $\left(\mathrm{CDCl}_{3}\right) \delta 7.53(1 \mathrm{H}, \mathrm{dd}, J=7.6,1.5 \mathrm{~Hz}, \mathrm{ArH}), 7.42(1 \mathrm{H}, \mathrm{d}, J=$ $16.4 \mathrm{~Hz}, \mathrm{CH}=\mathrm{CH}), 7.17(1 \mathrm{H}, \mathrm{dt}, J=7.7,1.6 \mathrm{~Hz}, \mathrm{ArH}), 7.01(4 \mathrm{H}, \mathrm{m}, 1 \mathrm{xCH}=\mathrm{CH}$, 3xArH), $6.77(1 \mathrm{H}, \mathrm{dd}, J=7.5,1.5 \mathrm{~Hz}, \mathrm{ArH}), 6.69(1 \mathrm{H}, \mathrm{dt}, J=7.7,1.6 \mathrm{~Hz}, \mathrm{ArH}), 4.97$ (1H, s, ArOH). $m / z 233\left(\mathrm{M}^{+}+1\right)$. Anal. $\left(\mathrm{C}_{14} \mathrm{H}_{10} \mathrm{~F}_{2} \mathrm{O}\right) \mathrm{C}, \mathrm{H}$.

(E)-1-hydroxy-4-(3,4-difluoro)styrylbenzene (5ix). White solid. Yield = 97\%. $\mathrm{mp}=$ 182-183 ${ }^{\circ} \mathrm{C} .{ }^{1} \mathrm{H}$ NMR $\left(\mathrm{CDCl}_{3}\right) \delta 7.71(2 \mathrm{H}, \mathrm{dd}, J=8.7,2.3 \mathrm{~Hz}, \mathrm{ArH}), 7.44(3 \mathrm{H}, \mathrm{m}$, $1 \times \mathrm{CH}=\mathrm{CH}, 2 \mathrm{xArH}), 7.26(2 \mathrm{H}, \mathrm{dd}, J=8.3,2.0 \mathrm{~Hz}, \mathrm{ArH}), 7.17(2 \mathrm{H}, \mathrm{m}, 1 \mathrm{xCH}=\mathrm{CH}$, 1xArH). $m / z, 233\left(\mathrm{M}^{+}+1\right)$. Anal. $\left(\mathrm{C}_{14} \mathrm{H}_{10} \mathrm{~F}_{2} \mathrm{O}\right) \mathrm{C}, \mathrm{H}$.

(E)-1-hydroxy-3-(3,4-difluoro)styrylbenzene (5iy). White solid. Yield = 32\%. $\mathrm{mp}=$ 95-96 ${ }^{\circ} \mathrm{C} .{ }^{1} \mathrm{H}$ NMR $\left(\mathrm{CDCl}_{3}\right) 7.72(1 \mathrm{H}, \mathrm{m}, \mathrm{ArH}), 7.48(1 \mathrm{H}, \mathrm{m}, \mathrm{ArH}), 7.17(6 \mathrm{H}, \mathrm{m}$, 2xCH=CH, 4xArH), $6.71(1 \mathrm{H}, \mathrm{dd}, J=8.0,1.6 \mathrm{~Hz}, \mathrm{ArH}) . \mathrm{m} / z 233\left(\mathrm{M}^{+}+1\right)$. Anal. $\left(\mathrm{C}_{14} \mathrm{H}_{10} \mathrm{~F}_{2} \mathrm{O}\right) \mathrm{C}, \mathrm{H}$.

(E)-1-hydroxy-2-(3,4-difluoro)styrylbenzene (5iz). White solid. Yield $=41 \% \cdot \mathrm{mp}=$ 123-124 ${ }^{\circ} \mathrm{C} .{ }^{1} \mathrm{H}$ NMR $\left(\mathrm{CDCl}_{3}\right) 7.53(1 \mathrm{H}, \mathrm{dd}, J=7.6,1.7 \mathrm{~Hz}, \mathrm{ArH}), 7.16(7 \mathrm{H}, \mathrm{m}$, 2xCH=CH, 5xArH), $6.83(1 \mathrm{H}, \mathrm{dd}, J=7.7,1.6 \mathrm{~Hz}, \mathrm{ArH}), 4.97(1 \mathrm{H}, \mathrm{s}, \mathrm{ArOH}) . m / z 233$ $\left(\mathrm{M}^{+}+1\right)$. Anal. $\left(\mathrm{C}_{14} \mathrm{H}_{10} \mathrm{~F}_{2} \mathrm{O}\right) \mathrm{C}, \mathrm{H}$. 
${ }^{\text {S16 }}$ (E)-1-hydroxy-4-(3,5-dimethoxy)styrylbenzene (5jx). Yellow oil. Yield $=93 \%$.

${ }^{1} \mathrm{H}$ NMR $\left(\mathrm{CDCl}_{3}\right) \delta 7.46(2 \mathrm{H}, \mathrm{d}, J=8.6 \mathrm{~Hz}, \mathrm{H}-3, \mathrm{H}-5), 7.10(1 \mathrm{H}, \mathrm{d}, J=16.5 \mathrm{~Hz}$, $\mathrm{CH}=\mathrm{CH}), 6.96(1 \mathrm{H}, \mathrm{d}, J=16.5 \mathrm{~Hz}, \mathrm{CH}=\mathrm{CH}), 6.88(2 \mathrm{H}, \mathrm{d}, J=8.5 \mathrm{~Hz}, \mathrm{ArH}), 6.69$ (2H, d, $J=8.6 \mathrm{~Hz}, \mathrm{H}-2, \mathrm{H}-6), 6.42(1 \mathrm{H}, \mathrm{t}, J=7.6 \mathrm{~Hz}, \mathrm{ArH}), 4.84(1 \mathrm{H}, \mathrm{s}, \mathrm{ArOH}), 3.87$ $\left(6 \mathrm{H}, \mathrm{s}, 2 \mathrm{xOCH} \mathrm{H}_{3}\right) . \mathrm{m} / \mathrm{z} 257\left(\mathrm{M}^{+}+1\right)$. Anal. $\left(\mathrm{C}_{16} \mathrm{H}_{16} \mathrm{O}_{2}\right) \mathrm{C}, \mathrm{H}$.

(E)-1-hydroxy-3-(3,5-dimethoxy)styrylbenzene (5jy). Brown oil. Yield $=77 \% .{ }^{1} \mathrm{H}$ NMR $\left(\mathrm{CDCl}_{3}\right) \delta 7.44(1 \mathrm{H}, \mathrm{t}, J=7.6 \mathrm{~Hz}, \mathrm{ArH}), 7.17(4 \mathrm{H}, \mathrm{m}, 2 \mathrm{xCH}=\mathrm{CH}, 2 \mathrm{xArH}), 7.02$ $(1 \mathrm{H}, \mathrm{dd}, J=7.6,1.5 \mathrm{~Hz}, \mathrm{ArH}), 6.87(2 \mathrm{H}, \mathrm{d}, J=7.6 \mathrm{~Hz}, \mathrm{ArH}), 6.64(1 \mathrm{H}, \mathrm{t}, J=7.6 \mathrm{~Hz}$, ArH), $\left.4.00(6 \mathrm{H}, \mathrm{s}, 2 \mathrm{xOCH})_{3}\right) . m / z, 257\left(\mathrm{M}^{+}+1\right)$. Anal. $\left(\mathrm{C}_{16} \mathrm{H}_{16} \mathrm{O}_{2}\right) \mathrm{C}, \mathrm{H}$.

(E)-1-hydroxy-2-(3,5-dimethoxy)styrylbenzene (5jz). Grey solid. Yield $=84 \% .{ }^{1} \mathrm{H}$ NMR (DMSO) $\delta 9.81(1 \mathrm{H}, \mathrm{bs}, \mathrm{ArOH}), 7.56(1 \mathrm{H}, \mathrm{dd}, J=7.7,1.5 \mathrm{~Hz}, \mathrm{ArH}), 7.41(1 \mathrm{H}$, $\mathrm{d},, J=16.5 \mathrm{~Hz}, \mathrm{CH}=\mathrm{CH}), 7.17(1 \mathrm{H}, \mathrm{d}, J=16.5 \mathrm{~Hz}, \mathrm{CH}=\mathrm{CH}), 7.12(1 \mathrm{H}, \mathrm{dt}, J=7.6$, $1.5 \mathrm{~Hz}, \mathrm{ArH}), 6.88(1 \mathrm{H}, \mathrm{dd}, J=7.6,0.9 \mathrm{~Hz}, \mathrm{ArH}), 6.83(1 \mathrm{H}, \mathrm{dt}, J=7.6,0.9 \mathrm{~Hz}, \operatorname{ArH})$, $6.71(2 \mathrm{H}, \mathrm{d}, J=2.2 \mathrm{~Hz}, \mathrm{ArH}), 6.83(1 \mathrm{H}, \mathrm{t}, J=2.2 \mathrm{~Hz}, \mathrm{ArH}), 3.78(6 \mathrm{H}, \mathrm{s}, 2 \mathrm{xOCH})_{3}$. $m / z 257\left(\mathrm{M}^{+}+1\right)$. Anal. $\left(\mathrm{C}_{16} \mathrm{H}_{16} \mathrm{O}_{2}\right) \mathrm{C}, \mathrm{H}$.

\section{In Vitro Assays.}

\section{Growth Inhibition Studies}

The human tumour cell lines HCT116, HT29 (colon) and MCF7 and MDA MB 468 (breast) were cultured in RPMI1640 media supplemented with 10\% foetal bovine serum at $37^{\circ} \mathrm{C}$ in $5 \% \mathrm{CO}_{2}$. The ability of hydroxylated stilbenes to inhibit the growth 
${ }^{\mathrm{S} 17}$ of the cells was measured by Thiazolyl Blue Tetrazolium Bromide (MTT) assay. Cells were plated into 96 well microtitre plates and allowed to attach overnight. Following $72 \mathrm{~h}$ incubation with serially diluted hydroxylated stilbenes MTT was added to a final concentration of $400 \mu \mathrm{g} / \mathrm{ml}$. The media was aspirated following $4 \mathrm{~h}$ incubation and the formazan product solubilised in 4:1 DMSO:glycine buffer $(\mathrm{pH}$ 10.5). The absorbance at 550nm was recorded using an Anthos (Labtech) plate reader. Results are expressed as the concentration of compound required to inhibit $50 \%$ control cell growth $\left(\mathrm{GI}_{50}\right)$. A control plate was set up and the MTT assay carried out to ascertain the initial absorbance at the time of exposure to hydroxylated stilbenes. 
${ }^{\text {S18 }}$ Table 1: Cell Growth Inhibitory $\left(\mathrm{GI}_{50} / \mu \mathrm{M}\right)$ Activity of Compounds 5ax - 5jz (tested in triplicate)

\begin{tabular}{|c|c|c|}
\hline Compound & НCТ 116 & MDA MB 468 \\
\hline resveratrol & 49.6 & 41.1 \\
\hline $5 \mathbf{a x}$ & 39.6 & 13.0 \\
\hline 5 ay & 57.4 & 7.8 \\
\hline $5 \mathbf{a z}$ & 58.1 & 24.9 \\
\hline $5 b x$ & 29.7 & 5.5 \\
\hline 5 by & 60.3 & 6.1 \\
\hline $5 \mathrm{bz}$ & 53.1 & 6.2 \\
\hline $5 c x$ & 37.4 & 7.2 \\
\hline $5 \mathrm{cy}$ & 62.0 & 3.1 \\
\hline $5 \mathrm{cz}$ & 58.0 & 3.1 \\
\hline $5 d x$ & 51.3 & 3.3 \\
\hline $5 d y$ & 42.3 & 2.7 \\
\hline $5 \mathrm{dz}$ & 50.3 & 25.7 \\
\hline $5 e x$ & 21.0 & 8.1 \\
\hline $5 e y$ & 58.0 & 4.7 \\
\hline $5 e z$ & 52.7 & 11.3 \\
\hline $\mathbf{5 f} \mathbf{x}$ & 40.3 & 7.7 \\
\hline $5 f y$ & 44.2 & 2.1 \\
\hline $5 f z$ & 56.1 & 14.3 \\
\hline $5 g x$ & 38.5 & 2.8 \\
\hline $5 g y$ & 58.0 & 1.4 \\
\hline
\end{tabular}




$\begin{array}{lll}\mathbf{5 g z} & 60.8 & 20.5 \\ \mathbf{5 h x} & 30.2 & 6.0 \\ \mathbf{5 h y} & 39.4 & 15.7 \\ \mathbf{5 h z} & 35.2 & 12.8 \\ \mathbf{5 i x} & 18.1 & 19.1 \\ \mathbf{5 i y} & 36.0 & 1.6 \\ \mathbf{5 i z} & 15.6 & 1.1 \\ \mathbf{5 j \mathbf { x }} & 30.0 & 2.1 \\ \mathbf{5 j y} & 43.1 & 0.96 \\ \mathbf{5 j z} & 21.3 & 2.5\end{array}$

\section{${ }^{\text {S19}}$ Cell Cycle Analysis}

The effects of hydroxylated stilbenes on the cell cycle distribution of HCT116 and MDA MB 468 cells was studied by flow cytometric analysis of cellular DNA content essentially as described by Nicoletti and co-workers. ${ }^{10}$ MDA MB 468 and HCT116 cells were treated with $10 \mu \mathrm{M}$ hydroxylated stilbenes or DMSO for $48 \mathrm{~h}$. Floating cells were collected, attached cells trypsinised then pooled together with the floaters. Following two washes in PBS cells were resuspended in $400 \mu$ fluorochrome solution containing $50 \mu \mathrm{g} / \mathrm{ml}$ propidium iodide $(\mathrm{PI}), 100 \mu \mathrm{g} / \mathrm{ml}$ ribonuclease $\mathrm{A}, 0.1 \%$ sodium citrate and $0.1 \%$ Triton-X100 for $1 \mathrm{~h}$ at $4{ }^{\circ} \mathrm{C}$ in the dark. The DNA content was analysed by flow cytometry. Data was collected using an Epics XL flow cytometer (Beckman Coulter) and analysed with EXPO32 software. PI fluorescence was collected in FL3 using a doublet discrimination method. Results are expressed as \% 
${ }^{\mathrm{S} 20}$ cell population in any given phase of the cell cycle. Cells with sub G0/1 DNA content are designated as potentially apoptotic.

\section{AnnexinV-FITC/propidium iodide Analysis of Apoptosis}

An early apoptotic event is the translocation of phosphatidylserine (PS) from the inner to the outer membrane leaflet of the cell. This can be detected using fluorosceinlabeled annexinV (annexinV-FITC), a $\mathrm{Ca}^{2+}$-dependent phopholipid-binding protein with high affinity for PS. Combined with PI (used as an indicator of cell integrity) a measure of percentage cell population in early apoptosis can be achieved.

Induction of apoptosis was assayed using an annexinV apoptosis detection kit (Santa Cruz). Cells were treated as they were for cell cycle analysis. Following the PBS washes $1 \times 10^{5}$ cells were resuspended in $100 \mu \mathrm{l}$ assay buffer and $5 \mu \mathrm{l}$ annexinV-FITC added. After $15 \mathrm{~min}$ incubation at RTP in the dark, $400 \mu \mathrm{l}$ assay buffer and $10 \mu \mathrm{l}$ propidium iodide solution $(10 \mu \mathrm{g} / \mathrm{ml})$ were added. Cells were then analysed by flow cytometry. Annexin V-FITC fluorescence was collected in FL1 and propidium iodide fluorescence collected in FL3. Cells showing increased FL1 fluorescence without a concurrent increase in FL3 fluorescence are considered to be in early apoptosis. Where an increase is seen in both fluorescence channels, the cells are considered to be in either late apoptosis or to have undergone necrosis.

\section{Fluorescence microscopy}

Cells were treated as they were for cell cycle analysis. Following the PBS washes the cells were resuspended in $10 \mu \mathrm{g} / \mathrm{ml}$ acridine orange, spotted on glass slides and 
${ }^{\text {S21 }}$ visualized under a fluorescence microscope (Leica Dialux 20). Photomicrographs were taken using a Nikon Coolpix 4500 digital camera. Cells showing shrinkage accompanied by chromatin condensation and marginalization are defined as being apoptotic.

\section{Microanalytical Data}

\begin{tabular}{|c|c|c|c|c|c|}
\hline Compound & $\mathbf{R}_{1}$ & $\mathbf{R}_{2}$ & formula & $\mathrm{C} \%$ & $\mathrm{H} \%$ \\
\hline $5 \mathbf{a x}$ & $\mathrm{H}$ & $4-\mathrm{OH}$ & $\begin{array}{c}\mathrm{C}_{14} \mathrm{H}_{12} \mathrm{O} \text { (calc.) } \\
\text { found }\end{array}$ & $\begin{array}{l}85.68 \\
85.49\end{array}$ & $\begin{array}{l}6.16 \\
6.19\end{array}$ \\
\hline 5 ay & $\mathrm{H}$ & $3-\mathrm{OH}$ & $\begin{array}{c}\mathrm{C}_{14} \mathrm{H}_{12} \mathrm{O} \text { (calc.) } \\
\text { Found }\end{array}$ & $\begin{array}{l}85.68 \\
85.72\end{array}$ & $\begin{array}{l}6.16 \\
6.39\end{array}$ \\
\hline $5 \mathbf{a z}$ & $\mathrm{H}$ & $2-\mathrm{OH}$ & $\begin{array}{c}\mathrm{C}_{14} \mathrm{H}_{12} \mathrm{O} \text { (calc.) } \\
\text { Found }\end{array}$ & $\begin{array}{l}85.68 \\
85.51\end{array}$ & $\begin{array}{l}6.16 \\
6.27 \\
\end{array}$ \\
\hline $5 b x$ & 4-OMe & $4-\mathrm{OH}$ & $\begin{array}{c}\mathrm{C}_{15} \mathrm{H}_{14} \mathrm{O}_{2} \text { (calc.) } \\
\text { Found }\end{array}$ & $\begin{array}{l}79.62 \\
79.44\end{array}$ & $\begin{array}{l}6.24 \\
5.94\end{array}$ \\
\hline 5by & 4-OMe & $3-\mathrm{OH}$ & $\begin{array}{c}\mathrm{C}_{15} \mathrm{H}_{14} \mathrm{O}_{2} \text { (calc.) } \\
\text { Found }\end{array}$ & $\begin{array}{l}79.62 \\
79.19\end{array}$ & $\begin{array}{l}6.24 \\
6.31\end{array}$ \\
\hline $5 \mathrm{bz}$ & 4-OMe & $2-\mathrm{OH}$ & $\begin{array}{c}\mathrm{C}_{15} \mathrm{H}_{14} \mathrm{O}_{2} \text { (calc.) } \\
\text { Found }\end{array}$ & $\begin{array}{l}79.62 \\
79.66\end{array}$ & $\begin{array}{l}6.24 \\
6.21\end{array}$ \\
\hline $5 \mathrm{cx}$ & 3-OMe & $4-\mathrm{OH}$ & $\begin{array}{c}\mathrm{C}_{15} \mathrm{H}_{14} \mathrm{O}_{2} \text { (calc.) } \\
\text { Found }\end{array}$ & $\begin{array}{l}79.62 \\
79.51\end{array}$ & $\begin{array}{l}6.24 \\
6.26 \\
\end{array}$ \\
\hline $5 \mathrm{cy}$ & 3-OMe & $3-\mathrm{OH}$ & $\begin{array}{c}\mathrm{C}_{15} \mathrm{H}_{14} \mathrm{O}_{2} \text { (calc.) } \\
\text { Found }\end{array}$ & $\begin{array}{l}79.62 \\
79.38 \\
\end{array}$ & $\begin{array}{l}6.24 \\
6.25 \\
\end{array}$ \\
\hline $5 \mathrm{cz}$ & 3-OMe & $2-\mathrm{OH}$ & $\begin{array}{c}\mathrm{C}_{15} \mathrm{H}_{14} \mathrm{O}_{2} \text { (calc.) } \\
\text { Found }\end{array}$ & $\begin{array}{l}79.62 \\
79.22\end{array}$ & $\begin{array}{l}6.24 \\
6.18\end{array}$ \\
\hline $5 d x$ & 2-OMe & $4-\mathrm{OH}$ & $\begin{array}{c}\mathrm{C}_{15} \mathrm{H}_{14} \mathrm{O}_{2} \text { (calc.) } \\
\text { Found }\end{array}$ & $\begin{array}{l}79.62 \\
79.23\end{array}$ & $\begin{array}{l}6.24 \\
6.25 \\
\end{array}$ \\
\hline $5 d y$ & 2-OMe & $3-\mathrm{OH}$ & $\begin{array}{c}\mathrm{C}_{15} \mathrm{H}_{14} \mathrm{O}_{2} \text { (calc.) } \\
\text { Found }\end{array}$ & $\begin{array}{l}79.62 \\
79.39\end{array}$ & $\begin{array}{l}6.24 \\
6.60\end{array}$ \\
\hline $5 \mathrm{dz}$ & 2-OMe & $2-\mathrm{OH}$ & $\begin{array}{c}\mathrm{C}_{15} \mathrm{H}_{14} \mathrm{O}_{2} \text { (calc.) } \\
\text { Found }\end{array}$ & $\begin{array}{l}79.62 \\
79.87\end{array}$ & $\begin{array}{l}6.24 \\
6.31\end{array}$ \\
\hline 5 ex & $4-\mathrm{F}$ & $4-\mathrm{OH}$ & $\begin{array}{c}\mathrm{C}_{14} \mathrm{H}_{11} \mathrm{FO} \text { (calc.) } \\
\text { Found }\end{array}$ & $\begin{array}{l}78.49 \\
78.11\end{array}$ & $\begin{array}{l}5.18 \\
5.55\end{array}$ \\
\hline 5 ey & $4-\mathrm{F}$ & $3-\mathrm{OH}$ & $\begin{array}{c}\mathrm{C}_{14} \mathrm{H}_{11} \mathrm{FO} \text { (calc.) } \\
\text { Found }\end{array}$ & $\begin{array}{l}78.49 \\
78.53\end{array}$ & $\begin{array}{l}5.18 \\
5.18\end{array}$ \\
\hline $5 \mathrm{ez}$ & $4-\mathrm{F}$ & $2-\mathrm{OH}$ & $\begin{array}{c}\mathrm{C}_{14} \mathrm{H}_{11} \mathrm{FO} \text { (calc.) } \\
\text { Found }\end{array}$ & $\begin{array}{l}78.49 \\
78.15 \\
\end{array}$ & $\begin{array}{l}5.18 \\
5.50\end{array}$ \\
\hline $5 f x$ & $3-\mathrm{F}$ & $4-\mathrm{OH}$ & $\begin{array}{c}\mathrm{C}_{14} \mathrm{H}_{11} \mathrm{FO} \text { (calc.) } \\
\text { Found }\end{array}$ & $\begin{array}{l}78.49 \\
78.37\end{array}$ & $\begin{array}{l}5.18 \\
5.29\end{array}$ \\
\hline $5 f y$ & $3-F$ & $3-\mathrm{OH}$ & $\mathrm{C}_{14} \mathrm{H}_{11} \mathrm{FO}$ (calc.) & 78.49 & 5.18 \\
\hline
\end{tabular}




\begin{tabular}{|c|c|c|c|c|c|}
\hline & & & Found & 78.31 & 5.34 \\
\hline \multirow[t]{2}{*}{$5 f z$} & $3-\mathrm{F}$ & $2-\mathrm{OH}$ & $\mathrm{C}_{14} \mathrm{H}_{11} \mathrm{FO}$ (calc.) & 78.49 & 5.18 \\
\hline & & & Found & 78.31 & 5.30 \\
\hline \multirow[t]{2}{*}{$5 g x$} & $2-\mathrm{F}$ & $4-\mathrm{OH}$ & $\mathrm{C}_{14} \mathrm{H}_{11} \mathrm{FO}$ (calc.) & 78.49 & 5.18 \\
\hline & & & Found & 78.43 & 5.54 \\
\hline \multirow[t]{2}{*}{$5 g y$} & $2-\mathrm{F}$ & $3-\mathrm{OH}$ & $\mathrm{C}_{14} \mathrm{H}_{11} \mathrm{FO}$ (calc.) & 78.49 & 5.18 \\
\hline & & & Found & 78.26 & 5.43 \\
\hline \multirow[t]{2}{*}{$5 g z$} & $2-\mathrm{F}$ & $2-\mathrm{OH}$ & $\mathrm{C}_{14} \mathrm{H}_{11} \mathrm{FO}$ (calc.) & 78.49 & 5.18 \\
\hline & & & Found & 78.13 & 5.43 \\
\hline \multirow[t]{2}{*}{$5 \mathrm{hhx}$} & $3,5-\mathrm{F}_{2}$ & $4-\mathrm{OH}$ & $\mathrm{C}_{14} \mathrm{H}_{10} \mathrm{~F}_{2} \mathrm{O}$ (calc.) & 72.41 & 4.34 \\
\hline & & & Found & 72.68 & 4.51 \\
\hline \multirow[t]{2}{*}{5 hy } & $3,5-\mathrm{F}_{2}$ & $3-\mathrm{OH}$ & $\mathrm{C}_{14} \mathrm{H}_{10} \mathrm{~F}_{2} \mathrm{O}$ (calc.) & 72.41 & 4.34 \\
\hline & & & Found & 72.35 & 4.48 \\
\hline \multirow[t]{2}{*}{$5 \mathrm{hz}$} & $3,5-\mathrm{F}_{2}$ & $2-\mathrm{OH}$ & $\mathrm{C}_{14} \mathrm{H}_{10} \mathrm{~F}_{2} \mathrm{O}$ (calc.) & 72.41 & 4.34 \\
\hline & & & Found & 72.51 & 4.40 \\
\hline \multirow[t]{2}{*}{$5 i x$} & $3,4-\mathrm{F}_{2}$ & $4-\mathrm{OH}$ & $\mathrm{C}_{14} \mathrm{H}_{10} \mathrm{~F}_{2} \mathrm{O}$ (calc.) & 72.41 & 4.34 \\
\hline & & & Found & 72.73 & 4.26 \\
\hline \multirow[t]{2}{*}{$5 i y$} & $3,4-\mathrm{F}_{2}$ & $3-\mathrm{OH}$ & $\mathrm{C}_{14} \mathrm{H}_{10} \mathrm{~F}_{2} \mathrm{O}$ (calc.) & 72.41 & 4.34 \\
\hline & & & Found & 72.46 & 4.38 \\
\hline \multirow[t]{2}{*}{$5 \mathrm{iz}$} & $3,4-\mathrm{F}_{2}$ & $2-\mathrm{OH}$ & $\mathrm{C}_{14} \mathrm{H}_{10} \mathrm{~F}_{2} \mathrm{O}$ (calc.) & 72.41 & 4.34 \\
\hline & & & Found & 72.15 & 4.57 \\
\hline \multirow[t]{2}{*}{$5 \mathbf{j} x$} & $3,5-\mathrm{OMe}_{2}$ & $4-\mathrm{OH}$ & $\mathrm{C}_{16} \mathrm{H}_{16} \mathrm{O}_{3}$ (calc.) & 74.98 & 6.29 \\
\hline & & & Found & 75.14 & 6.32 \\
\hline \multirow[t]{2}{*}{$5 \mathbf{j y}$} & $3,5-\mathrm{OMe}_{2}$ & $3-\mathrm{OH}$ & $\mathrm{C}_{16} \mathrm{H}_{16} \mathrm{O}_{3}$ (calc.) & 74.98 & 6.29 \\
\hline & & & Found & 74.66 & 6.41 \\
\hline \multirow[t]{2}{*}{$5 \mathbf{j j z}$} & $3,5-\mathrm{OMe}_{2}$ & $2-\mathrm{OH}$ & $\mathrm{C}_{16} \mathrm{H}_{16} \mathrm{O}_{3}$ (calc.) & 74.98 & 6.29 \\
\hline & & & Found & 74.91 & 6.35 \\
\hline
\end{tabular}

S21 


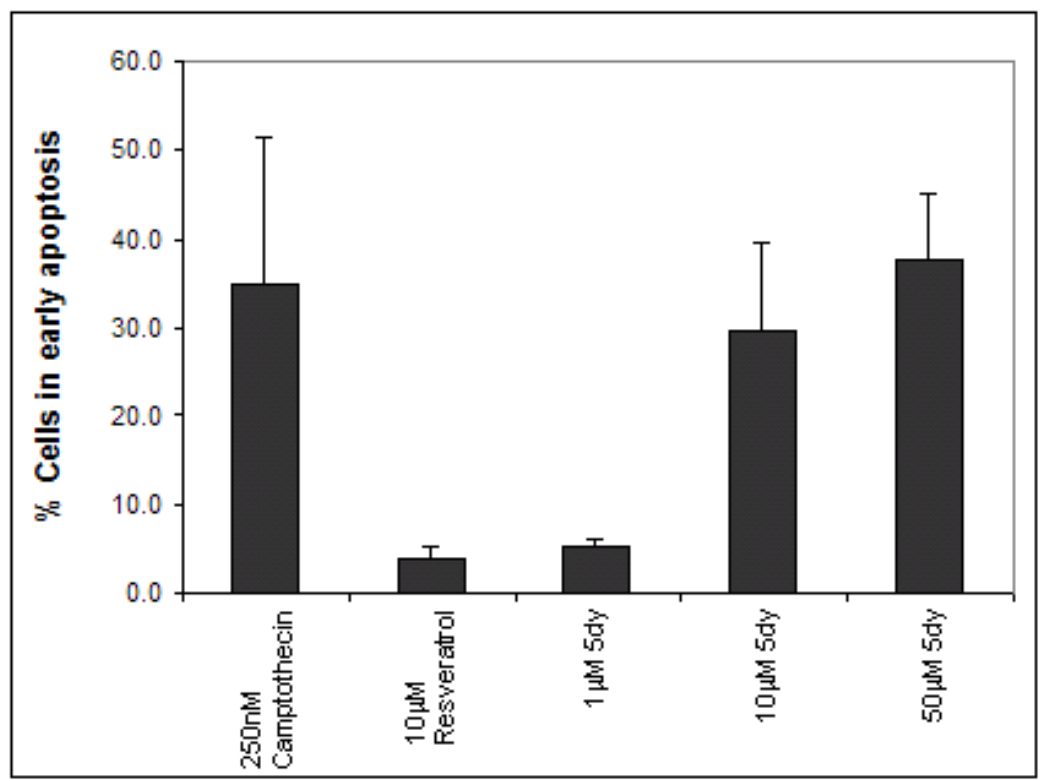

Figure S1. AnnexinV-PI analysis in MDA MB 468 cells, following 48 h drug treatment with camptothecin $(250 \mathrm{nM})$, resveratrol $(10 \mu \mathrm{M})$, and dose-response profile of compound $\mathbf{5 d y}(1,10$ and $50 \mu \mathrm{M})$, demonstrating early apoptotic events (an increase in AnnexinV-FITC binding) without concurrent increase in PI staining. Means of 3 repeats +/- SEM. 